Article

\title{
Differential Game Analysis of Scientific Crowdsourcing on Knowledge Transfer
}

\author{
Guohao Wang (1) and Liying Yu *(1) \\ School of Management, Shanghai University, Shanghai 200444, China; guohaowang@shu.edu.cn \\ * Correspondence: yuliying@shu.edu.cn; Tel.: +86-138-1828-1950
}

Received: 7 April 2019; Accepted: 8 May 2019; Published: 14 May 2019

\begin{abstract}
Scientific crowdsourcing based on knowledge transfer between enterprises has drawn wide attention. This paper constructs the Stackelberg master-slave game model and the benefit sharing model. Through the model comparison and numerical simulation, the knowledge transfer behavior and the revenue distribution mechanism of crowdsourcing initiator and solver in the context of scientific crowdsourcing are studied. The research shows that the knowledge transfer quality and the crowdsourcing total revenue under the benefit sharing state are better than the Stackelberg master-slave game under the leadership of the crowdsourcing initiator and when the revenue distribution coefficient between the crowdsourcing initiator and solver is within a certain range. The final revenue for each party in the benefit sharing state is higher than the one in the Stackelberg master-slave game state. In addition, the research finds that the knowledge coupling degree between the initiator and the solver has a positive impact on knowledge transfer and crowdsourcing benefits. The conclusions of this paper provide a theoretical basis for enterprises, especially for large-scale high-tech business to business enterprises, to transfer knowledge and distribute revenue and eventually improve their scientific crowdsourcing quality.
\end{abstract}

Keywords: scientific crowdsourcing; knowledge transfer; knowledge coupling degree; revenue distribution

\section{Introduction}

The concept of crowdsourcing was first proposed by the American scholar Jeff Howe in 2006, referring to the act of a company or institution taking a function once performed by employees and outsourcing it to an undefined network of people in the form of an open call [1]. Broadly speaking, crowdsourcing is a distributed internet business model that can provide innovative thinking and new ways for organizations to explore creative ideas, solve problems in research and development (R\&D) processes, effectively control operation costs for organizations, and eventually achieve breakthrough innovation. The generation of crowdsourcing can be attributed to the enterprise's reflection on the traditional innovation model. The enterprise R\&D model has gone through the process of internal $R \& D$, outsourcing $R \& D$ to crowdsourcing $R \& D$, and its characteristics range from internal resource integration to external business cooperation, and finally evolve into a mass knowledge transfer driver in crowdsourcing, as shown in Figure 1. 


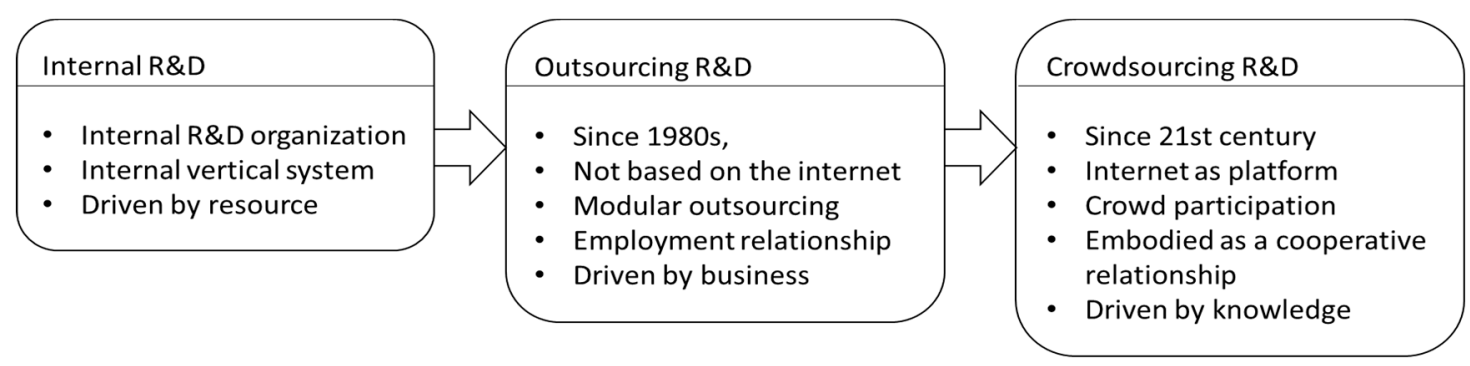

Figure 1. Enterprise R\&D model evolvement.

Scientific crowdsourcing is a new way of contemporary scientific research activities [2,3], which is the product of technological development and internet popularization. For crowdsourcing R\&D as shown in Figure 1, from an innovation mechanism's point of view, scientific crowdsourcing can be composed of two core parts: one is the crowdsourcing platform as an integrated intermediary, which acts as a collector of individual thoughts of the crowd members [4]; the other one is the knowledge-based collaboration module, which consists of knowledge production, knowledge dissemination, knowledge absorption, and knowledge consumption [5]. By gathering the wisdom of the crowd, which is usually constituted by researchers and institutions, scientific crowdsourcing is aimed at solving the critical challenges in science and especially in leading-edge technology.

From a knowledge transfer point of view, it has always been an issue of industrialization, and earlier forms of knowledge transfer involved user-developer interactions, out of which both knowledge transfer and crowdsourcing emerged [6]. With the recent development of the internet, open innovation has become a promising strategy for firms searching for external solutions to resolve internal problems, and scientific crowdsourcing, a type of open innovation [7], is a process of knowledge flow, which includes knowledge gathering, knowledge dissemination, knowledge absorption, knowledge integration, and knowledge application from a solver via a crowdsourcing platform to the initiator. Many prior scholars used versatile methods to analyze the process of knowledge transfer, including game, agency, resource-based, and transaction costs theories [8-11]. Especially game theory has been widely used in the knowledge transfer of product innovation [12], the knowledge transfer between smaller and larger companies [13], the knowledge sharing behavior of employees [14], and so forth. To probe the mechanism of knowledge transfer in scientific crowdsourcing, this paper is set out to answer the following research question: How do firms determine the best strategy by using game theory to improve knowledge transfer behavior and revenue during scientific crowdsourcing?

The rest of the paper is organized as follows: the related literature is reviewed in Section 2. Model assumptions, notations, and formulations are developed in Section 3. In Section 4, numerical simulations and discussions are presented. Finally, some concluding remarks are provided in Section 5.

\section{Literature Review}

The concept and evolution of knowledge creation has long been studied in past decades. One of the most classical models is the dynamic knowledge creation model, known as the SECI model by Nonaka and Takeuchi [15], which includes four quadrants with tacit knowledge assets on the left and explicit knowledge assets on the right to facilitate the generation, transfer, and application of knowledge. In the spiral of different levels of knowledge creation, the tacit knowledge is transformed as the explicit one through socialization, externalization, combination, and internalization, so that new knowledge is created as one of the organization knowledge assets [16]. Some studies have shown that scientific crowdsourcing can enhance the organization's ability to absorb knowledge, including the identification, assimilation, internalization, and use of knowledge [17,18]. Ghezzi et al. [19] think knowledge management is an important process of scientific crowdsourcing. Previous studies found that enterprises absorb new knowledge and effectively use new knowledge through knowledge transfer, which is essential for enterprises to improve their competitive advantage and enhance organization vitality $[5,20]$. With the development of technology and the application of the internet, the product life 
cycle is shortened, and the pace of technology updates is accelerating [21]. It is difficult for enterprises to rely on their own independent research, development, and technological innovation to meet market demand, and at the same time, it will generate large costs and risks. As a result, many companies tend to establish partnerships with external partners and enhance innovation value through knowledge transfer [22,23]. Witt et al. [24] studied the particular features of knowledge to be transferred-overt propositional versus tacit procedural. According to the theory of absorptive capacity, some scholars found that companies with higher absorptive capacity are more likely to transfer complex knowledge and create value [25]. Wang et al. [26] believe that there are four basic modules for knowledge transfer, including the knowledge sender, knowledge receiver, knowledge characteristics, and knowledge transfer path. Xie et al. [27] believe that the recipient's ability to absorb knowledge is critical to the innovation performance of high-tech companies. Some studies find that knowledge attributes and knowledge characteristics [28-30] can also affect the effectiveness of knowledge transfer. In addition, Galati et al. [31] developed an innovative model for knowledge transfer, including key factors like partners' similarities before starting R\&D relationships, co-opetition situations, knowledge leakage, opportunistic behavior, and reputation issues.

An important driving force for the rise of scientific crowdsourcing is the contradiction between the resources needed to organize scientific research activities and the ability to acquire resources. That is, the amount of organizational resources is always behind the demand for resources. The value of scientific crowdsourcing can be embodied in many different forms, and prior research mainly focused on different elements which may affect the value of crowdsourcing, such as the crowdsourcing platform, motivation of the crowd, knowledge process, and so forth, all of which have been explored in qualitative analysis approaches. Wang et al. [32] believe that the knowledge value extraction process of crowdsourcing includes four dimensions: information exchange, knowledge trading, information dissemination, and public evaluation. Helander et al. [33] find that crowdsourcing value is mainly divided into direct value and indirect value. The direct value includes a profit function, volume function, and safeguard function, and the indirect value includes an innovation function, market function, scout function, and access function. Bernhardt et al. [34] analyze the value that research crowdsourcing brings to organizations in four aspects: user stickiness, technology complementarity, product innovation, and R\&D efficiency. Knowledge as an important form of resources is the medium of communication between the initiator and the solver. Zhang et al. [35] study the impact of network embedding and media embedding on the willingness of crowdsourcing individual knowledge. Pollok et al. [7] find that establishing a clear and articulated knowledge process within the organization improves crowdsourcing activities. Some studies conclude that the crowdsourcing solver is the individual participant who has mastered various knowledge elements [36,37], but others think that the organization has the potential to participate in scientific crowdsourcing as a crowdsourcing solver [38]. Xue et al. [39] have studied that knowledge transfer, knowledge collaboration effect, knowledge transfer cost, and knowledge transfer potential are three key factors in crowdsourcing impacting the knowledge transfer behavior.

So far, many scholars have conducted in-depth research on knowledge transfer and its influencing factors, and other scholars have fully explored the mode and value of scientific crowdsourcing. With the emergence of new ways of scientific research activities, it is increasingly necessary to bring together interdisciplinary scientific and technical personnel, and scientific research organizations optimize the allocation and use of scientific and technological resources and promote the flow and application of knowledge among different organizations. Facing the current challenges, adopting a new model of scientific crowdsourcing for knowledge transfer can effectively improve the efficiency of R\&D innovation, reduce transaction costs, and shorten the time for the transformation of scientific and technological achievements. However, the existing research is less involved in the quantification analysis of scientific crowdsourcing, especially using game theory to investigate the process of scientific crowdsourcing. In the process of scientific crowdsourcing, the initiator holds the resources and funds, while the solver has the creativity and technology. Both parties need to work together to improve the quality of knowledge transfer and make reasonable revenue distributions. It is very important to 
understand the balance of knowledge transfer investment and revenue. Therefore, the knowledge transfer decision-making behavior of the crowdsourcing subject can be understood as the process of the game between the initiator and the solver [40]. The game theory discussed in this paper enables us to decide strategically in scientific crowdsourcing activities, such as knowledge transfer, which is basically an interactive decision-making process.

This paper uses the game method to study the following three aspects: First of all, how do the crowdsourcing participants determine their knowledge transfer behavior based on the Stackelberg master-slave game model and the benefit sharing model? Secondly, what is the total revenue of the scientific crowdsourcing under the two game states, and how do the initiator and solver build the best revenue distribution mechanism? In the end, the impact of the knowledge coupling degree between the initiator and the solver is also investigated.

\section{Model Formulation}

\subsection{Scientific Crowdsourcing Knowledge Transfer Mechanism}

For the scientific crowdsourcing knowledge transfer, from the perspective of the crowdsourcing subject, the two ends of the knowledge flow are the initiator and the solver, respectively; hence, the knowledge absorption ability of the initiator and the knowledge dissemination ability of the solver [25-27] are key factors affecting the knowledge transfer. Considering that the effect of knowledge transfer is also related to knowledge attributes and knowledge characteristics [28-30], that is, the degree of knowledge matching between the initiator and the solver, this paper defines the knowledge coupling degree as one of the key factors impacting scientific crowdsourcing knowledge transfer. The knowledge coupling degree is a measure of the degree of knowledge association and mutual influence between the initiator and the solver. The strength of the coupling depends on the knowledge type of the crowdsourcing, the knowledge complexity, and the knowledge complementarity.

Based on effective knowledge flow in scientific crowdsourcing, the initiator and solver would pay knowledge transfer costs and gain revenue, respectively. The balance between costs and revenue is the key to measuring the success of scientific crowdsourcing. This paper establishes a scientific crowdsourcing knowledge transfer flow chart, as shown in Figure 2.

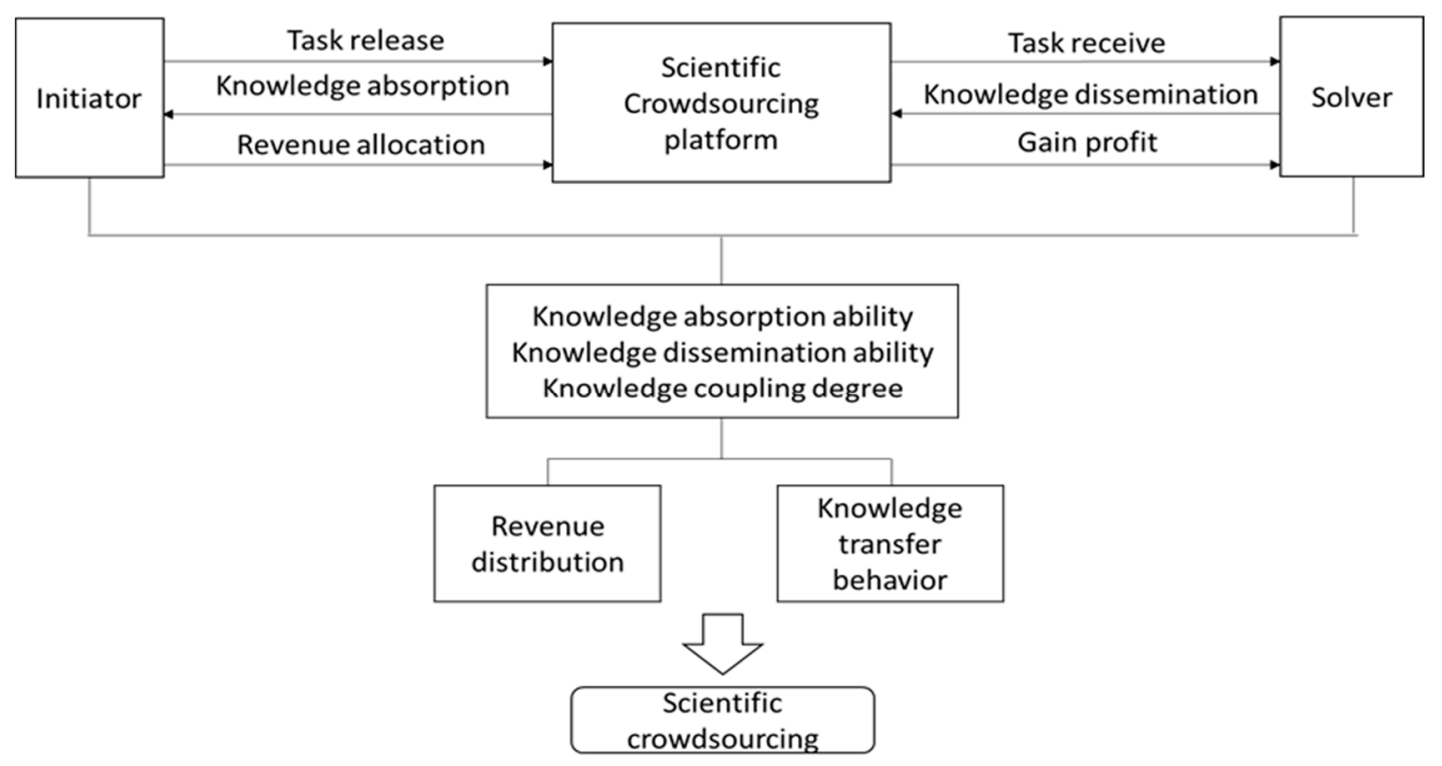

Figure 2. Scientific crowdsourcing knowledge transfer flow chart.

Judging from the game relationship between the crowdsourcing parties, there are two situations: Stackelberg game model dominated by one party, usually the initiator, and benefit sharing model. 
(1) Scientific crowdsourcing under the Stackelberg master-slave game model: The knowledge gap between initiator and solver leads to the asymmetry of resources in the innovation process of scientific crowdsourcing, especially for large enterprises, research institutes, universities, and so on, which have an advantage in information, capital, technology, and so forth. If the initiator always maximizes its own interests in the knowledge transfer and funds allocation, it will constitute the Stackelberg master-slave game dominated by the initiator. In the Stackelberg master-slave game, the initiator determines its knowledge transfer behavior and revenue distribution coefficient first. After the solver observes the decision of the initiator, it determines its own knowledge transfer behavior to maximize its own revenue. Generally, enterprises that have advantages in resources, information, and market, especially those that have achieved monopoly status, will adopt their own dominant Stackelberg master-slave games, such as military and aerospace companies.

(2) Scientific crowdsourcing under the benefit sharing model: The initiator and solver usually have their own advantages in each unique technology, through the complementarity of advanced technologies and the allocation of advantageous resources. Based on equal cooperation, the information between the two parties can be fully exchanged, and the knowledge transfer cooperation has better execution. The goal for each participant is exactly the same as the overall scientific crowdsourcing goal, which means both the initiator and the solver would determine their knowledge transfer behavior based on the overall benefit maximization. Generally, enterprises with complementary advantages in resources, information, and market will adopt a benefit sharing model, especially those enterprises that are fully market-oriented, such as integrated circuits and communication industries.

\subsection{Game Model Construction and Solution}

\subsubsection{Model Assumption and Parameters Description}

This paper only considers two crowdsourcing entities consisting of the enterprise as the initiator and the organization as the solver. The solver is the supplier that provides the knowledge needed for scientific crowdsourcing, including information, method, or consulting services. The purpose of scientific crowdsourcing is to improve the quality of the knowledge transfer to obtain revenue. In the process of scientific crowdsourcing, the enterprise, which is the crowdsourcing initiator, will provide the required task description, resources, money, and so forth.

Assume that both the initiator and the solver know all the information about the cost of the knowledge transfer behavior and the distribution of the crowdsourcing income, and each of them develops their own knowledge transfer decision with the goal of maximizing their own interests. In order to better describe the problem, the paper also makes the following basic assumptions:

The scientific crowdsourcing relationship has been established. The knowledge transfer architecture model of the enterprise as the initiator and the organization as the solver has been formed.

The quality of the knowledge transfer under the scientific crowdsourcing mode depends on the knowledge transfer ability of the solver, the knowledge absorption ability of the initiator and the knowledge coupling degree of both parties. The knowledge transfer quality during scientific crowdsourcing is a process that changes dynamically with time [41]. Referring to the research method of $\mathrm{Fu}$ [42], the following dynamic equation can be used to describe the dynamic change of the knowledge transfer quality:

$$
\frac{\partial Q(t)}{\partial t}=\left[\alpha I_{u p}(t)+\beta I_{\text {down }}(t)\right] * k-\gamma Q(t)
$$

where $Q(t)$ represents the knowledge transfer quality at the time $t, I_{u p}(t)$ represents the knowledge dissemination ability of the solver at the time $t$, and $I_{\text {down }}(t)$ represents the knowledge absorption ability of the initiator at the time $t$. Both $I_{\text {up }}(t)$ and $I_{\text {down }}(t)$ are greater than zero. $\alpha$ represents the coefficient of the influence of the solver's knowledge dissemination ability on the final knowledge transfer quality. $\beta$ represents the coefficient of the influence of the initiator's knowledge absorption ability on the final knowledge transfer quality. $k$ represents the knowledge coupling degree between the initiator and 
the solver. $\gamma$ represents the natural decay rate of the knowledge transfer quality when the knowledge transfer effort of the crowdsourcing participants is zero. $\alpha, \beta, \gamma$, and $\mathrm{k}$ are all constants in the range of 0 to 1.

Considering an actual situation, in order to improve the value of scientific crowdsourcing, it is necessary to increase the investment in knowledge transfer between the initiator and the solver. With reference to Dong et al. [43] on the assumption of knowledge transfer cost, the following formula can be used to express the cost of knowledge transfer for the initiator and solver:

$$
C=\frac{\varepsilon}{2} I^{2}(t)
$$

where $\varepsilon$ is the knowledge transfer cost coefficient, and $\varepsilon$ is a constant larger than zero.

Assuming that other influencing factors remain unchanged, the value of scientific crowdsourcing increases as the quality of knowledge transfer increases. Based on Zhang et al.'s hypothesis about the relationship between product quality and revenue [44], combined with the research purpose of this paper, the value of scientific crowdsourcing is a linear function of knowledge transfer quality:

$$
S=\eta+\lambda Q(t)
$$

where $\eta$ is a constant, and $\lambda$ is the influence coefficient of knowledge transfer quality on the final scientific crowdsourcing value.

For revenue from scientific crowdsourcing, the revenue allocated to the solver can be directly set to $\theta \times S$, and the revenue allocated to the initiator is $(1-\theta) \times S, \theta \in[0,1]$.

Assume that the initiator and the solver have the same discount factor $\mu$, which is greater than zero and less than one.

Based on above assumptions, in order to have a clear and thorough understanding of the model details, it is necessary to summarize and combine all parameters and descriptions, as shown in the following Table 1.

Table 1. Model parameter description.

\begin{tabular}{cc}
\hline Parameter & Description \\
\hline$\alpha$ & Influence coefficient of the solver's knowledge dissemination ability on final knowledge transfer quality \\
$\beta$ & Influence coefficient of the initiator's knowledge absorption ability on final knowledge transfer quality \\
$\gamma$ & The natural decay rate of knowledge transfer quality when knowledge transfer effort is zero \\
$k$ & Knowledge coupling degree of between initiator and solver \\
$\theta$ & Revenue distribution coefficient \\
$\mu$ & Discount factor \\
$\varphi$ & Cost sharing coefficient \\
$\lambda$ & Influence coefficient of knowledge transfer quality on the final scientific crowdsourcing value \\
$\eta$ & Constant \\
$Q$ & Knowledge transfer quality \\
$\varepsilon_{\text {up }}$ & Solver's knowledge transfer cost coefficient \\
$\varepsilon_{\text {down }}$ & Initiator's knowledge transfer cost coefficient \\
$I_{\text {up }}$ & Solver's knowledge dissemination ability \\
$I_{\text {down }}$ & Initiator's knowledge absorption ability \\
$C_{\text {up }}$ & Solver's knowledge dissemination cost \\
$C_{\text {down }}$ & Initiator's knowledge absorption cost \\
$V_{\text {up }}$ & Solver's scientific crowdsourcing revenue objective function \\
$V_{\text {down }}$ & Initiator's scientific crowdsourcing revenue objective function \\
\hline
\end{tabular}

Furthermore, in order to facilitate the calculation and comparison of the knowledge transfer behavior and revenue in two different games, in this model, the knowledge transfer ability of the initiator and the solver of the Stackelberg game are $I_{\text {down } 1}$ and $I_{\text {up } 1}$, respectively, and the revenues are $V_{\text {down } 1}$ and $V_{\text {up } 1}$, respectively, and the total revenue is $V_{1}$. The knowledge transfer ability of the initiator and the solver of the benefit sharing state are $I_{\text {down } 2}$ and $I_{\text {up } 2}$, respectively, the revenues are $V_{\text {down } 2}$ and $V_{\text {up2 }}$, respectively, and the total return is $V_{2}$. 


\subsubsection{The Stackelberg Game Model Led by the Initiator}

For the game between the crowdsourcing initiator and the solver, it generally sets the initiator as the focal subject. In order to stimulate the knowledge transfer behavior, the initiator not only pays for its own knowledge absorption cost, but also pays part of the knowledge dissemination cost of the solver to improve the total knowledge transfer quality. In this case, the initiator, as the leader in the Stackelberg game, first determines the knowledge absorption capacity and the cost-sharing coefficient, which is denoted as $\varphi$, and $\varphi$ is in the range of 0 to 1 . The solver acts as a follower and sees the action of the initiator before making a decision on their knowledge dissemination behavior. The initiator can anticipate the follow-up response of the solver before making a decision to achieve static feedback of the Stackelberg equilibrium.

Under this model, the cost function $C_{\text {down }}$ of the initiator and the cost function $C_{u p}$ of the solver are, respectively:

$$
\left\{\begin{array}{l}
C_{\text {down }}=\frac{\varepsilon_{\text {down }}}{2} I_{\text {down }}^{2}(t)+\varphi \frac{\varepsilon_{u p}}{2} I_{\text {up }}^{2}(t) \\
C_{\text {up }}=(1-\varphi) \frac{\varepsilon_{\text {up }}}{2} I_{u p}^{2}(t)
\end{array}\right.
$$

The ultimate goal of the initiator and the solver to participate in scientific crowdsourcing is to maximize the return. The revenue generated by the crowdsourcing minus the knowledge transfer cost constitutes the final benefit. The optimization problems for the initiator and solver are, respectively, as follows:

$$
\begin{aligned}
& \left\{\begin{array}{l}
V_{\text {down }}=\max _{I_{\text {down }}} \int_{0}^{\infty} e^{-u t}\left\{(1-\theta)[\eta+\lambda Q(t)]-\frac{\varepsilon_{\text {down }}}{2} I_{\text {down }}^{2}(t)-\varphi \frac{\varepsilon_{u p}}{2} I_{\text {up }}^{2}(t)\right\} d t \\
\text { s.t. } \\
\frac{\partial Q(t)}{\partial t}=\left[\alpha I_{\text {up }}(t)+\beta I_{\text {down }}(t)\right] * k-\gamma Q(t) \\
0 \leq \alpha, \beta, \gamma, k, \varphi, \theta, \mu \leq 1 \\
\varepsilon \geq 0 \\
I_{\text {up }}(t), I_{\text {down }}(t) \geq 0
\end{array}\right. \\
& \qquad\left\{\begin{array}{l}
V_{\text {up }}=\max _{I_{\text {up }}} \int_{0}^{\infty} e^{-\mu t}\left\{\theta[\eta+\lambda Q(t)]-(1-\varphi) \frac{\varepsilon_{\text {up }}}{2} I_{\text {up }}^{2}(t)\right\} d t \\
\text { s.t. } \\
\frac{\partial Q(t)}{\partial t}=\left[\alpha I_{\text {up }}(t)+\beta I_{\text {down }}(t)\right] * k-\gamma Q(t) \\
0 \leq \alpha, \beta, \gamma, k, \varphi, \theta, \mu \leq 1 \\
\varepsilon \geq 0 \\
I_{\text {up }}(t), I_{\text {down }}(t) \geq 0
\end{array}\right.
\end{aligned}
$$

Using the reverse induction method, the knowledge transfer behavior of the solver is first determined. Assume that the optimal value objective function $V_{\text {down }}$ and $V_{u p}$ of the initiator and the solver are continuous bounded function with respect to the quality of the knowledge transfer. Since the decision of the solver is to follow the decision of the initiator, this optimal control problem can be directly solved. According to the optimal control principle, for all $Q \geq 0$, the optimal value function $V_{u p}$ satisfies the partial differential equation, which is also called Hamilton-Jacobi-Bellman equation [45], as shown below (for convenience, the time $t$ will be omitted below):

$$
\mu V_{u p}=\max _{I_{u p}}\left\{\theta(\eta+\lambda Q)-(1-\varphi) \frac{\varepsilon_{u p}}{2} I_{u p}^{2}+V_{u p}^{\prime}\left[\left(\alpha I_{u p}+\beta I_{\text {down }}\right) k-\gamma Q\right]\right\}
$$

The optimality condition of Equation (7) is when the first derivative of $I_{u p}$ is equal to zero. $I_{u p}{ }^{*}$ can be derived as follows:

$$
I_{u p}^{*}=\frac{k \alpha V_{u p}^{\prime}}{(1-\varphi) \varepsilon_{u p}}
$$


The crowdsourcing initiator determines their decision based on the knowledge transfer behavior of the solver. With Equations (5) and (8), the optimal value function of the contractor should meet the equation as follows:

$$
\begin{aligned}
& \mu V_{\text {down }}=\max _{I_{\text {down }}}\left\{(1-\theta)(\eta+\lambda Q)-\frac{\varepsilon_{\text {down }}}{2} I_{\text {down }}^{2}-\varphi \frac{\varepsilon_{\text {up }}}{2}\left[\frac{k \alpha V_{\text {up }}^{\prime}}{(1-\varphi) \varepsilon_{\text {up }}}\right]^{2}\right. \\
& \left.+V_{\text {down }}^{\prime}\left[\left(\alpha \frac{k \alpha V_{u p}}{(1-\varphi) \varepsilon_{\text {up }}}+\beta I_{\text {down }}\right) * k-\gamma Q\right]\right\}
\end{aligned}
$$

By considering partial derivatives of Equation (9) and setting them equal to 0, the following results can be derived:

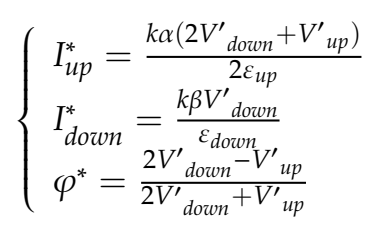

By resolving Equation (8) with Equation (7) and resolving Equation (10) with Equation (9), the following results are derived:

$$
\begin{aligned}
& V_{u p}^{*}=\frac{1}{\mu}\left[\theta \eta+\frac{k^{2} \alpha^{2}\left(2 V_{d o w n}^{\prime}+V_{u p}^{\prime}\right) V_{u p}^{\prime}}{4 \varepsilon_{u p}}+\frac{k^{2} \beta^{2} V^{\prime}{ }_{\text {oown }} V^{\prime}{ }_{u p}}{\varepsilon_{\text {down }}}\right]+\frac{\lambda \theta-\gamma V_{u p}^{\prime}}{\mu} Q \\
& V_{\text {down }}^{*}=\frac{1}{\mu}\left[(1-\theta) \eta+\frac{k^{2} \alpha^{2}\left(2 V_{\text {down }^{\prime}}+V^{\prime}{ }_{\text {up }}\right)^{2}}{8 \varepsilon_{\text {up }}}+\frac{k^{2} \beta^{2} V_{\text {down }^{\prime}}{ }^{2}}{2 \varepsilon_{\text {down }}}\right]+\frac{\lambda(1-\theta)-\gamma V_{\text {down }}^{\prime}}{\mu} Q
\end{aligned}
$$

By getting the derivatives of $Q$ in Equations (11) and (12) and make them equal to 0, the following results can be derived:

$$
\left\{\begin{array}{l}
V_{\text {up }}^{\prime}=\frac{\lambda \theta}{\mu+\gamma} \\
V_{\text {down }}^{\prime}=\frac{\lambda(1-\theta)}{\mu+\gamma}
\end{array}\right.
$$

By resolving Equation (13) with Equations (10)-(12), the following results can be derived:

$$
\begin{gathered}
\left\{\begin{array}{l}
I_{\text {up }}^{*}=\frac{k \alpha \lambda(2-\theta)}{2 \varepsilon_{u p}(\mu+\gamma)} \\
I_{\text {down }}^{*}=\frac{k \beta \lambda(1-\theta)}{\varepsilon_{\text {down }}(\mu+\gamma)} \\
\varphi^{*}=\frac{2-3 \theta}{2-\theta}
\end{array}\right. \\
V_{\text {up }}^{*}=\frac{1}{\mu}\left\{\theta \eta+\frac{\lambda^{2} \theta}{(\mu+\gamma)^{2}}\left[\frac{k^{2} \alpha^{2}(2-\theta)}{4 \varepsilon_{\text {up }}}+\frac{k^{2} \beta^{2}(1-\theta)}{\varepsilon_{\text {down }}}\right]\right\}+\frac{\lambda \theta}{\mu+\gamma} Q \\
V_{\text {down }}^{*}=\frac{1}{\mu}\left\{(1-\theta) \eta+\frac{\lambda^{2}}{(\mu+\gamma)^{2}}\left[\frac{k^{2} \alpha^{2}(2-\theta)^{2}}{8 \varepsilon_{\text {up }}}+\frac{k^{2} \beta^{2}(1-\theta)^{2}}{2 \varepsilon_{\text {down }}}\right]\right\}+\frac{\lambda(1-\theta)}{(\mu+\gamma)} Q
\end{gathered}
$$

\subsubsection{The Benefit Sharing Model}

Under the state of benefit sharing, each of the crowdsourcing participants moves in the same direction of maximizing self-interest and pursuing the maximization of the overall interests of scientific crowdsourcing cooperation, which is to determine the knowledge transfer behavior according to the overall benefit maximization. The optimization problem is: 


$$
\left\{\begin{array}{l}
V=\max _{I_{\text {up }} I_{\text {down }}} \int_{0}^{\infty} e^{-\mu t}\left\{\eta+\lambda Q(t)-\frac{\varepsilon_{u p}}{2} I_{\text {up }}^{2}(t)-\frac{\varepsilon_{\text {down }}}{2} I_{\text {down }}^{2}(t)\right\} d t \\
\text { s.t. } \\
\frac{\partial Q(t)}{\partial t}=\left[\alpha I_{\text {up }}(t)+\beta I_{\text {down }}(t)\right] * k-\gamma Q(t) \\
0 \leq \alpha, \beta, \gamma, k, \mu \leq 1 \\
\varepsilon \geq 0 \\
I_{\text {up }}(t), I_{\text {down }}(t) \geq 0
\end{array}\right.
$$

The following is the optimal revenue function $V$ :

$$
\mu V=\max _{I_{\text {up }} I_{\text {down }}}\left\{\eta+\lambda Q-\frac{\varepsilon_{\text {up }}}{2} I_{\text {up }}^{2}-\frac{\varepsilon_{\text {down }}}{2} I_{\text {down }}^{2}+V^{\prime}\left[\left(\alpha I_{\text {up }}+\beta I_{\text {down }}\right) k-\gamma Q\right]\right\}
$$

By getting the partial derivatives of $I_{u p}$ and $I_{\text {down }}$ in Equation (18) and making them equal to 0, the following results can be derived:

$$
\left\{\begin{array}{l}
I_{\text {up }}^{*}=\frac{k \alpha V^{\prime}}{\varepsilon_{\text {up }}} \\
I_{\text {down }}^{*}=\frac{k \beta V^{\prime}}{\varepsilon_{\text {down }}}
\end{array}\right.
$$

Substitute Equation (19) into Equation (18), then

$$
V^{*}=\frac{1}{\mu}\left(\eta+\frac{k^{2} \alpha^{2} V^{\prime 2}}{2 \varepsilon_{u p}}+\frac{k^{2} \beta^{2} V^{\prime 2}}{2 \varepsilon_{\text {down }}}\right)+\frac{\lambda-\gamma V^{\prime}}{\mu} Q
$$

Get the derivative of $Q$ in Equation (20) and make it equal to 0 . The following results can be derived:

$$
V^{\prime}=\frac{\lambda}{\mu+\gamma}
$$

Substitute Equation (21) into Equations (19) and (20). Then the knowledge dissemination ability of the solver, the knowledge absorption ability of the initiator, and the overall revenue of scientific crowdsourcing can be derived as follows:

$$
\begin{gathered}
\left\{\begin{array}{l}
I_{\text {up }}^{*}=\frac{k \alpha \lambda}{\varepsilon_{u p}(\mu+\gamma)} \\
I_{\text {down }}^{*}=\frac{k \beta \lambda}{\varepsilon_{\text {down }}(\mu+\gamma)}
\end{array}\right. \\
V^{*}=\frac{1}{\mu}\left[\eta+\frac{k^{2} \alpha^{2} \lambda^{2}}{2 \varepsilon_{\text {up }}(\mu+\gamma)^{2}}+\frac{k^{2} \beta^{2} \lambda^{2}}{2 \varepsilon_{\text {down }}(\mu+\gamma)^{2}}\right]+\frac{\lambda}{\mu+\gamma} Q
\end{gathered}
$$

\subsection{Comparison Analysis}

\subsubsection{Knowledge Transfer Behavior Comparison}

With Equations (14) and (22), the comparison of the knowledge transfer behavior of the initiator and solver in two different games are:

$$
\begin{gathered}
I_{u p 2}^{*}-I_{u p 1}^{*}=\frac{k \alpha \lambda \theta}{2 \varepsilon_{u p}(\mu+\gamma)}>0 \\
I_{\text {down } 2}^{*}-I_{\text {down } 1}^{*}=\frac{k \beta \theta \lambda}{\varepsilon_{\text {down }}(\mu+\gamma)}>0
\end{gathered}
$$

Based on Equations (24) and (25), the following proposition is derived:

Proposition 1. The knowledge transfer of the crowdsourcing subject in the state of benefit sharing is better than the Stackelberg game knowledge transfer under the leadership of one party. 


\subsubsection{Scientific Crowdsourcing Total Revenue Comparison}

For the Stackelberg master-slave game, based on Equations (15) and (16), the total revenue $V_{1}{ }^{*}$ of scientific crowdsourcing can be derived as follows:

$$
V_{1}^{*}=V_{\text {up }}^{*}+V_{\text {down }}^{*}=\frac{1}{\mu}\left\{\eta+\frac{\lambda^{2}}{(\mu+\gamma)^{2}}\left[\frac{k^{2} \alpha^{2}\left(4-\theta^{2}\right)}{8 \varepsilon_{\text {up }}}+\frac{k^{2} \beta^{2}\left(1-\theta^{2}\right)}{2 \varepsilon_{\text {down }}}\right]\right\}+\frac{\lambda}{(\mu+\gamma)} Q
$$

For the benefit sharing model, the total revenue $V_{2}{ }^{*}$ of scientific crowdsourcing has been calculated by Equation (23), so that the difference in the total revenue between the two models is denoted as follows:

$$
V_{2}^{*}-V_{1}^{*}=\frac{\lambda^{2}}{\mu(\mu+\gamma)^{2}}\left[\frac{k^{2} \alpha^{2} \theta^{2}}{8 \varepsilon_{\text {up }}}+\frac{k^{2} \beta^{2} \theta^{2}}{2 \varepsilon_{\text {down }}}\right]>0
$$

The result of Equation (27) can be written formally:

Proposition 2. The total revenue of the scientific crowdsourcing in the benefit sharing state is higher than the total revenue in the Stackelberg game state under the leadership of the initiator.

\subsubsection{The Optimal Revenue Distribution Mechanism in Scientific Crowdsourcing}

For the Stackelberg game model led by the initiator, according to Equation (14), there is a unique solution to the cost sharing coefficient $\varphi^{*}$ when the Stackelberg game equilibrium is reached between the initiator and the solver. Since the cost sharing coefficient $\varphi^{*}$ meets the condition $0<\varphi^{*}<1$, it is:

$$
0 \leq \varphi^{*}=\frac{2-3 \theta}{2-\theta} \leq 1
$$

By solving Equation (28), the result obtained is $0 \leq \theta \leq \frac{2}{3}$ and can be written formally as follows.

Proposition 3. Under the Stackelberg game model led by the initiator, the revenue distribution coefficient should satisfy the condition $0 \leq \theta \leq \frac{2}{3}$.

Before determining the distribution of the crowdsourcing revenue, it is necessary to compare the total revenue of the scientific crowdsourcing cooperation under the two different game situations.

Although the total revenue of the initiator and solver are higher in the game of benefit sharing, this does not guarantee that the returns of each subject are also higher than the maximum benefit in the non-shared game. It is known from the principal-agent theory that if the total revenue distribution mechanism can satisfy the participation constraints of both the initiator and the solver, the benefit sharing model is Pareto optimal for them.

In the state of benefit sharing, the revenue of the initiator and solver are:

$$
\begin{gathered}
V_{\text {up } 2}^{*}=\frac{\theta}{\mu}\left(\eta+\frac{k^{2} \alpha^{2} \lambda^{2}}{2 \varepsilon_{u p}(\mu+\gamma)^{2}}+\frac{k^{2} \beta^{2} \lambda^{2}}{2 \varepsilon_{\text {down }}(\mu+\gamma)^{2}}\right)+\frac{\lambda \theta}{\mu+\gamma} Q \\
V_{\text {down } 2}^{*}=\frac{1-\theta}{\mu}\left(\eta+\frac{k^{2} \alpha^{2} \lambda^{2}}{2 \varepsilon_{\text {up }}(\mu+\gamma)^{2}}+\frac{k^{2} \beta^{2} \lambda^{2}}{2 \varepsilon_{\text {down }}(\mu+\gamma)^{2}}\right)+\frac{\lambda(1-\theta)}{\mu+\gamma} Q
\end{gathered}
$$

For each crowdsourcing participant, in order to achieve better revenue in benefit sharing mode than in Stackelberg game mode, the following equations should be met:

$$
\left\{\begin{array}{l}
V_{u p 2}^{*}-V_{u p 1}^{*} \geq 0 \\
V_{\text {down } 2}^{*}-V_{\text {down } 1}^{*} \geq 0
\end{array}\right.
$$


Based on Equations (15), (16), (29)-(31), the revenue distribution coefficient is in the following range:

$$
\frac{2 \beta^{2} \varepsilon_{\text {up }}}{4 \beta^{2} \varepsilon_{\text {up }}+\alpha^{2} \varepsilon_{\text {down }}} \leq \theta \leq \frac{4 \beta^{2} \varepsilon_{\text {up }}}{4 \beta^{2} \varepsilon_{\text {up }}+\alpha^{2} \varepsilon_{\text {down }}}
$$

Proposition 4. Under the benefit sharing of scientific crowdsourcing cooperation, the optimal revenue distribution coefficient of the initiator and the solver should satisfy Equation (32).

\section{Simulation and Discussion}

In order to have a direct and straightforward understanding of the above conclusions, this research used numerical analysis to simulate modeling results.

\subsection{Generic Simulation}

Assume the value of those parameters in the model are set as follows: $\alpha=0.8, \beta=0.6, k=0.8$, $\gamma=0.1, \theta=0.4, \mu=0.95, \lambda=0.8, \eta=1, \varepsilon_{u p}=0.5$, and $\varepsilon_{\text {down }}=0.5$. After calculation, the knowledge absorption ability of the initiator, the knowledge dissemination ability of the solver, and the optimal result of each revenue can be obtained under the two game situations, as shown in Table 2.

Table 2. Comparison of the results for the two game cases.

\begin{tabular}{cccc}
\hline & Stackelberg Master-Slave Game & Benefit Sharing & Difference \\
\hline$I_{\text {up }}$ & 0.819 & 1.024 & $20.00 \%$ \\
$I_{\text {down }}$ & 0.461 & 0.768 & $40.00 \%$ \\
$V_{\text {up }}$ & $0.569+0.305 Q$ & $0.577+0.305 Q$ & $1.52 \%$ \\
$V_{\text {down }}$ & $0.842+0.457 Q$ & $0.866+0.457 Q$ & $2.74 \%$ \\
$V$ & $1.411+0.762 Q$ & $1.444+0.762 Q$ & $2.25 \%$ \\
\hline
\end{tabular}

It can be seen from Table 2 that in the case of benefit sharing, the knowledge transfer between the initiator and the solver was greatly improved, especially for the initiator. The difference in knowledge transfer between the two games reached $40 \%$, indicating that the initiator's knowledge absorption ability is significantly improved in the case of benefit sharing. The total revenue and the revenue for each participant are also higher in the state of benefit sharing than in the state of the Stackelberg master-slave game.

\subsection{How Does the Revenue Distribution Coefficient Impact Revenue?}

Assume the value of those parameters in the model are set as follows: $\alpha=0.8, \beta=0.6, k=0.8$, $\gamma=0.1, \mu=0.95, \lambda=0.8, \eta=1, \varepsilon_{u p}=0.5$, and $\varepsilon_{\text {down }}=0.5$. According to Equation (32), the revenue distribution coefficient $\theta$ can be calculated to satisfy $0.346<\theta<0.692$. Figure 3a,b presents the comparison curves of the revenue of initiator and solver with the revenue distribution coefficient for the cases of two different games. 


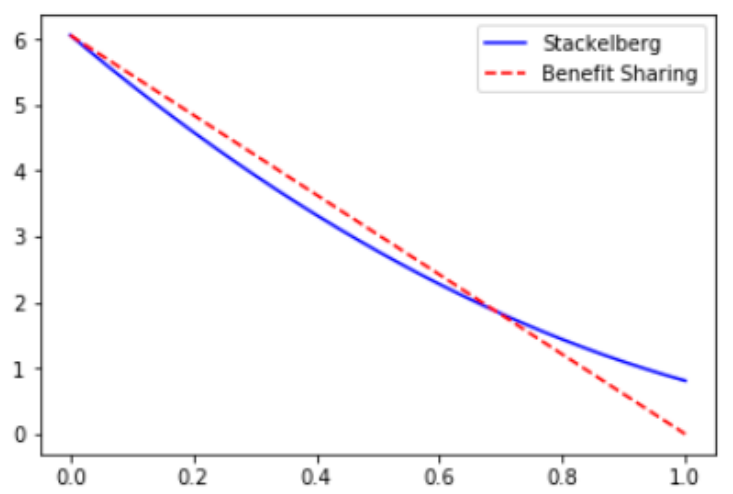

(a)

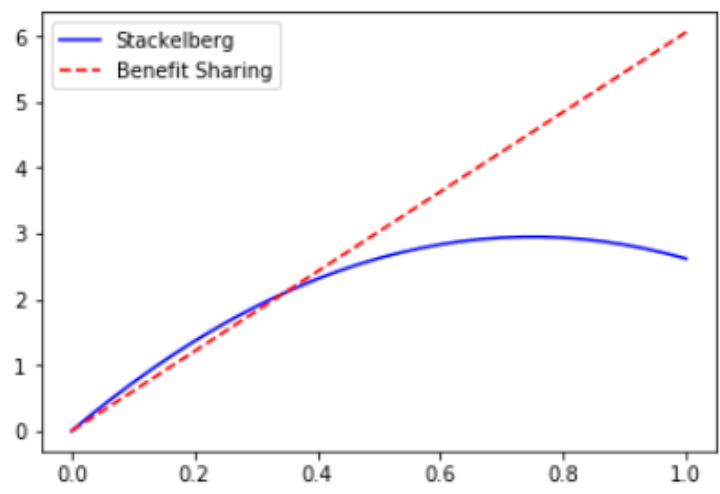

(b)

Figure 3. (a) Initiator's revenue vs. distribution coefficient; (b) solver's revenue vs. distribution coefficient.

It can be seen from the figures that when $\theta$ is less than 0.346 , the solver is has less revenue in the benefit sharing model than in the Stackelberg master-slave game model. When $\theta$ is greater than 0.692 , the initiator has less revenue in the benefit sharing model than in the Stackelberg master-slave game model. Only when $\theta$ is greater than 0.346 and less than 0.692 , both the initiator and the solver achieve more revenue in the benefit sharing game model than in the Stackelberg master-slave game model.

From the perspective of total revenue, regardless of the revenue distribution coefficient, the total revenue under the benefit sharing is unchanged and is greater than the total return of the Stackelberg master-slave game, as shown in Figure 4.

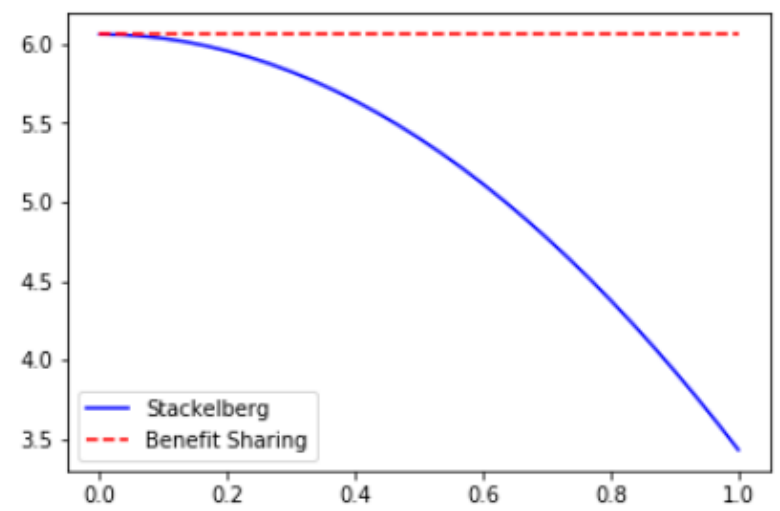

Figure 4. Total revenue vs. distribution coefficient.

4.3. Does the Knowledge Coupling Degree Play a Key Role in Regulating Knowledge Transfer Behavior and Revenue?

In order to analyze the knowledge coupling degree's regulation on the knowledge transfer behavior and revenue, assume the value of those parameters in the model are set as follows: $\alpha=0.8$, $\beta=0.6, \gamma=0.1, \mu=0.95, \lambda=0.8, \eta=1, \varepsilon_{u p}=0.5, \varepsilon_{\text {down }}=0.5$, and $\theta=0.4$. Simulations of the knowledge coupling degree $\mathrm{k}$ on knowledge transfer under the two different games are investigated, as shown in Figure 5a,b. 


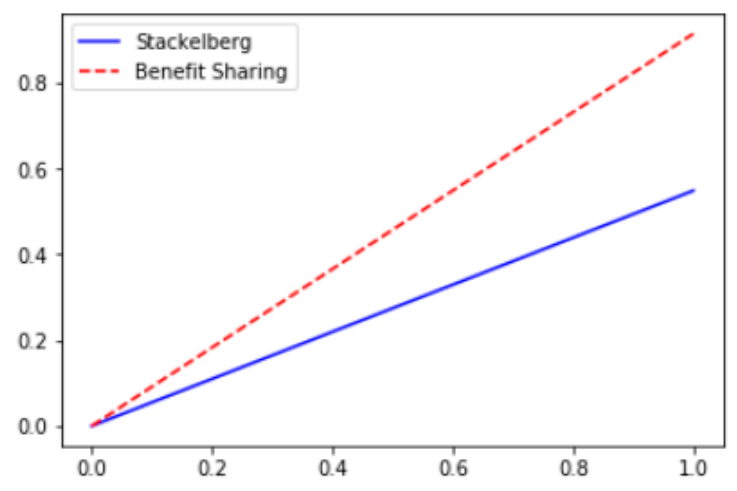

(a)

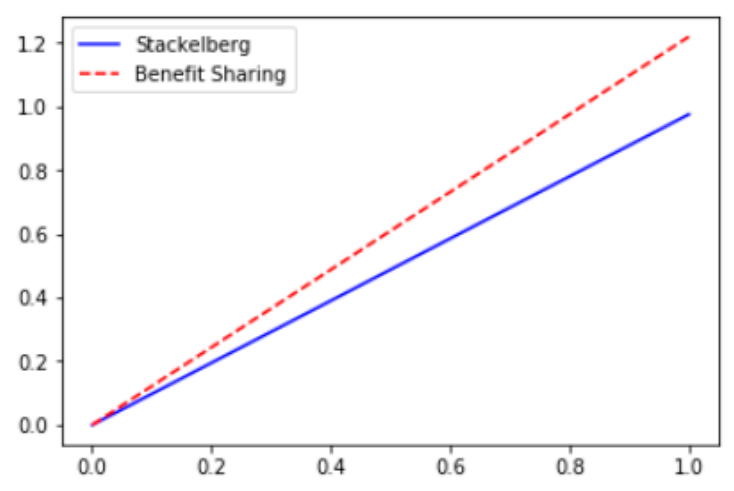

(b)

Figure 5. (a) Knowledge coupling degree impact on initiator's knowledge absorption ability; (b) knowledge coupling degree impact on solver's knowledge dissemination ability.

Figure $5 \mathrm{a}$ is the influence of the knowledge coupling degree on the initiator's knowledge dissemination ability, and Figure $5 \mathrm{~b}$ is the influence of the knowledge coupling degree on the solver's knowledge absorption ability. The figures show that the higher the knowledge coupling degree, the stronger the knowledge dissemination ability and knowledge absorption ability, thus achieving a higher knowledge transfer quality eventually. It can be further concluded that the absorption capacity of the initiator under the benefit sharing is significantly higher than that of the Stackelberg master-slave game, indicating that companies should try to establish a benefit sharing model with the solver in a scientific crowdsourcing cooperation.

The knowledge coupling degree also has a positive impact on the revenue of scientific crowdsourcing. The higher the knowledge coupling degree, the more revenue is achieved. From the simulation results, it can be seen that the initiator's and the solver's revenue achieved under the benefit sharing model is higher than the revenue achieved under the Stackelberg master-slave game model. The higher the degree of knowledge coupling between the initiator and the solver, the higher a synergy effect on knowledge transfer can be observed, as shown in Figure 6.

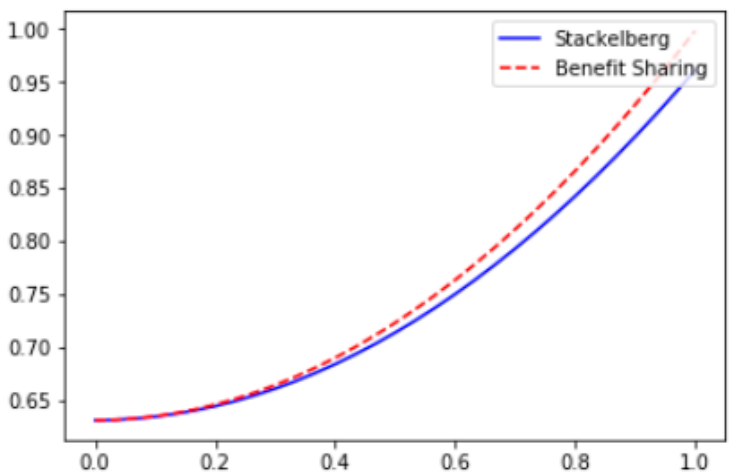

(a)

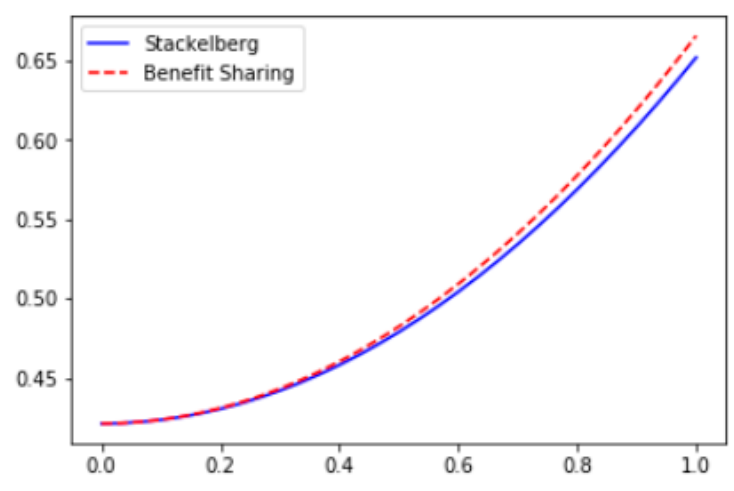

(b)

Figure 6. (a) Initiator's crowdsourcing revenue vs. knowledge coupling degree; (b) solver's crowdsourcing revenue vs. knowledge coupling degree.

\section{Conclusions}

This paper discusses the knowledge transfer and revenue distribution mechanism involving the crowdsourcing initiator and solver in a scientific crowdsourcing mode, examines the optimal knowledge transfer behavior of crowdsourcing in the two situations of Stackelberg master-slave game model and benefit sharing model, and analyzes the optimal total crowdsourcing revenue and the best revenue of each participant. Through comparative analysis and numerical simulation, the following 
conclusions can be drawn: (1) The knowledge transfer of crowdsourcing in the benefit sharing state is better than the Stackelberg master-slave game knowledge transfer under the leadership of the initiator; (2) The total revenue for scientific crowdsourcing is higher in the benefit sharing than in the Stackelberg master-slave game under the leadership of the initiator; (3) The revenue distribution coefficient affects the total revenue of the initiator and the solver in the two game situations. When the revenue distribution coefficient is under certain conditions, the revenue for each crowdsourcing participant under the benefit sharing model is higher than that under the Stackelberg master-slave game model; (4) The knowledge coupling degree of the initiator and solver can positively affect the knowledge transfer of scientific crowdsourcing, as well as revenue. The higher the degree of knowledge coupling, the stronger the knowledge dissemination ability and knowledge absorption ability, and the higher the final revenue.

The conclusions obtained by using the optimal control model and game analysis have important practical guiding significance for the research and development of large enterprises. For large-scale high-tech enterprises based on knowledge transfer as the main process of new product development (such as integrated circuits), universities, research institutes, and other organizations cooperating with core enterprises are generally in a weak position due to the large volume of core enterprises. In this case, the willingness of enterprises to build a benefit sharing cooperation model is generally low. This paper finds that the cooperation mechanism of scientific crowdsourcing should be based on the benefit sharing model. For this reason, the core enterprises should actively explore the model of benefit sharing with the related service enterprises in the upstream and downstream industry chain and adjust the revenue distribution coefficient to make both enterprises, and the ones in the chain, achieve relatively reasonable returns and motivate them with better enthusiasm and participation. The government can also establish various enterprise knowledge information databases, to find and match the partners with high knowledge coupling to the core enterprises, so that the collaboration quality of the enterprises and service vendors along the chain is improved.

The study also faces some limitations. For instance, the model proposed in this paper is only applicable when a scientific crowdsourcing relationship is established. The conclusions here are neither helpful for solvers to win scientific crowdsourcing contracts, nor for initiators to pick proper solvers. Besides, one of the model assumptions is that the knowledge transfer quality is changed as a function of time, which may not reflect reality, especially for some short-period projects or one-off projects. Moreover, this paper assumes the value of scientific crowdsourcing is a linear function of knowledge transfer quality. This might not be true when dealing with innovative and leading-edge technology transfer, which would not be a linear function but another form, such as an exponential function [46]. Although current results show important practical implications, future research could explore good approaches to quantify the parameters in the model, so that it can be used by firms. For example, the crowdsourcing initiator should establish a proper capability to judge internal knowledge characteristics, for example, tacit or explicit knowledge, as well as external crowd knowledge, and quantify them as knowledge distance and knowledge coupling degree. Furthermore, the research framework is based on one initiator and one solver, future research could extend this study by more solvers and initiators.

Author Contributions: All authors contributed equally to the research presented in this paper and to the preparation of the final manuscript.

Funding: The research was funded by the General Program of National Natural Science Foundation of China, "Research on Random Symmetrical Cone Complementarity Problems and Related Topics" (No: 11671250).

Acknowledgments: The authors thank the reviewers for their careful reading and providing some pertinent suggestions.

Conflicts of Interest: The authors declare no conflicts of interest. 


\section{References}

1. Howe, J. The rise of crowdsourcing. Wired Mag. 2006, 14, 1-4.

2. Wei, T.Q.; Jiang, T.; Tao, S.Y.; Xie, G.F.; Tan, Z.Y. Science sourcing-A new model of scientific cooperation. Sci. Manag. Res. 2015, 33, 16-19.

3. Zhang, J.Q. The impact of scientific crowdsourcing on Chinese scientific research activities. Forum Sci. Technol. China 2015, 3, 1.

4. Agafonovas, A.; Alonderiene, R. Value creation in innovation crowdsourcing: Example of creative agencies. Organ. Mark. Emerg. Econ. 2013, 2, 72-104.

5. Liu, Y.; Deng, P.; Wei, J.; Ying, Y.; Tian, M. International R\&D alliances and innovation for emerging market multinationals: Roles of environmental turbulence and knowledge transfer. J. Bus. Ind. Mark. 2019. [CrossRef]

6. Erkut, B. What Did SAP Change? A Market Shaping Analysis. Mark. Brand. Res. 2018, 5, 51-63. [CrossRef]

7. Pollok, P.; Luttgens, D.; Piller, F.T. How firms develop capability for crowdsourcing to increase open innovation performance: The interplay between organizational roles and knowledge processes. J. Prod. Innov. Manag. 2018. [CrossRef]

8. Fombrun, G.; Shanley, M. What's in a name: Reputation building and corporate strategy. Acad. Manag. J. 1990, 33, 233-258.

9. Brown, B.; Perry, S. Removing the financial performance halo from fortune's most admired companies. Acad. Manag. J. 1994, 37, 1347-1359.

10. Sedighi, M.; van Splunter, S.; Brazier, F.; van Beers, C.; Lukosch, S. Exploration of multi-layered knowledge sharing participation: The roles of perceived benefits and costs. J. Knowl. Manag. 2016, 20, 1247-1267. [CrossRef]

11. Biscotti, A.M.; D'Amico, E.; Monge, F. Do environmental management system affect the knowledge management process? The impact on the learning evolution and the relevance of organizational contect. Rev. Manag. Sci. 2018, 22, 603-620.

12. Luo, L.; Wang, J.R. Game Analysis of Knowledge Transfer of Product Innovation Team in Multinational Corporations. J. Hum. Res. Manag. 2017, 5, 63-69.

13. Chou, P.B.; Bandera, C.; Thomas, E. A behavioral game theory perspective on the collaboration between innovative and entrepreneurial firms. Int. J. Work Innocation 2017, 2, 6-31. [CrossRef]

14. Zhu, G.Y.; He, H.Y.; Fang, J.; Huang, J. Research on Knowledge Sharing Behavior of Employee based on Game Theory and Multi-Agent Situation from the Employee Position Perspective. Bol. Tec. 2017, 55, 262-271.

15. Nonaka, I.; Takeuchi, H. The Knowledge-Creating Company: How Japanese Companies Create the Dynamic of Innovation; Oxford University Press: Oxford, UK; Cary, NC, USA, 1995.

16. Nonaka, I.; Toyama, R.; Konno, N. SECI, Ba and leadership: A unified model of dynamic knowledge creation. Long Range Plan. 2000, 33, 5-34. [CrossRef]

17. King, A.A.; Lakhani, K.R. The contingent effect of absorptive capacity: An open innovation analysis. Harv. Bus. Sch. Work. Paper Ser. 2011, 21, 11-102. [CrossRef]

18. Spithoven, A.; Clarysse, B.; Knockaert, M. Building absorptive capacity to organize inbound open innovation in traditional industries. Technovation 2010, 31, 130-141. [CrossRef]

19. Ghezzi, A.; Gabelloni, D.; Martini, A.; Natalicchio, A. Crowdsourcing: A Review and Suggestions for Future Research. Int. J. Manag. Rev. 2017, 20, 343-363. [CrossRef]

20. Darr, E.; Argote, L.; Epple, D. The acquisition, transfer, and depreciation of knowledge in service organizations: Productivity in franchises. Manag. Sci. 1995, 41, 1750-1762. [CrossRef]

21. Tao, F.; Wang, Y.W.; Zuo, Y.; Yang, H.D.; Zhang, M. Internet of Things in product life-cycle energy management. J. Ind. Inf. Integr. 2016, 1, 26-39. [CrossRef]

22. Erkut, B. The Emergence of the ERP Software Market between Product Innovation and Market Shaping. J. Open Innov. Technol. Market Complex. 2018, 4, 23. [CrossRef]

23. Zhao, W.H.; Liang, Q.Z. Research on the relationship between technology acquisition methods and enterprise value. Stud. Sci. Sci. 2010, 28, 741-746+776.

24. Witt, U.; Zellner, C. How firm organizations adapt to secure a sustained knowledge transfer. Econ. Innov. New Technol. 2009, 18, 647-661. [CrossRef] 
25. Winkelbach, A.; Walter, A. Complex technological knowledge and value creation in science-to-industry technology transfer projects: The moderating effect of absorptive capacity. Ind. Mark. Manag. 2015, 47, 98-108. [CrossRef]

26. Wang, X.; Liu, W.; Li, K.K. Research on Influencing Factors of Collaborative Innovation Knowledge Transfer of Industry, University and Research Based on Dynamic Capability Theory. Inf. Sci. 2016, 34, 36-40.

27. Xie, X.; Zou, H.; Qi, G. Knowledge absorptive capacity and innovation performance in high-tech companies: A multi-mediating analysis. J. Bus. Res. 2018, 88, 289-297. [CrossRef]

28. Battistella, C.; De Toni, A.F.; Pillon, R. Inter-organisational technology/knowledge transfer: A framework from critical literature review. J. Technol. Transf. 2016, 41, 1195-1234. [CrossRef]

29. Cummings, J.; Sheng, T.B. Transferring R\&D knowledge: The key factors affecting knowledge transfer success. J. Eng. Technol. Manag. 2003, 20, 39-68.

30. De Wit-de Vries, E.; Dolfsma, W.A.; van der Windt, H.J. Knowledge transfer in university-industry research partnerships: A review. J. Technol. Transf. 2018. [CrossRef]

31. Galati, F.; Bigliardi, B. Redesigning the model of the initiative and evolution of inter-firm knowledge transfer in R\&D relationships. J. Knowl. Manag. 2019. [CrossRef]

32. Wang, S.; Yin, F.C. An analysis of knowledge valuation and organization respond of website-Based crowdsourcing. Sci. Res. Manag. 2017, 38, 35-42.

33. Helander, N.; Kärkkäinen, H.; Jussila, J. Value Creation in Business-To-Business Crowd Sourcing. Int. J. Knowl. Soc. Res. 2014, 5, 28-39. [CrossRef]

34. Bernhardt, J.; Helander, N.; Jussila, J.; Kärkkäinen, H. Crowdsourcing in Business-to-Business Markets: A Value Creation and Business Model Perspective. In Encyclopedia of E-Commerce Development, Implementation, and Management; IGI Global: Hershey, PA, USA, 2016; pp. 933-943.

35. Zhang, Y.Y.; Zhang, S.T.; Wu, C.H. Embedded or involved, why crowdsourcing individual contribute knowledge? Sci. Res. Manag. 2017, 38, 30-37.

36. Howe, J. Crowdsourcing: How the Power of the Crowd is Driving the Future of Business; Random House Business: New York, NY, USA, 2008.

37. Estellés-Arolas, E.; González-Ladrón-de-Guevara, F. Towards an integrated crowdsourcing definition. J. Inf. Sci. 2012, 38, 89-200. [CrossRef]

38. Jussila, J.; Kärkkäinen, H.; Leino, M. Learning from and with customers with social media: A model for social customer learning. Int. J. Manag. Knowl. Learn. 2012, 1, 5-25.

39. Xue, J.; Ding, C.Q.; Yuan, J. The evolutionary game study of knowledge transfer behavior in cooperative crowdsourcing community of innovation. Adv. Model. Anal. A 2016, 53, 164-175.

40. Jiang, Z.S.; Hu, L.Y. Analysis on knowledge transfer decisions in technology innovation alliance based on leader-Followers games. Sci. Res. Manag. 2011, 32, 19-25.

41. Ju, X.W.; Zhang, X.Z. Governance Model Construction of Inter-organizational Knowledge Transfer: The Role of Dissemination Capacity and Absorptive Capacity. Inf. Stud. Theory Appl. 2018, 41, 83-89.

42. Fu, Q.; Zeng, S.Q. Research on Differential Countermeasure Model of Vertical Cooperative Advertising. Syst. Eng. Theory Pract. 2007, 27, 26-33.

43. Dong, G.M.; Lin, M.; Lei, Z.H. Enterprise Knowledge Transfer Strategy under Competitive Conditions and Its Impact on Industrial Evolution. Chin. J. Manag. 2014, 11, 1246-1252.

44. Zhang, X.H.; Chen, J.F.; Huang, P. Analysis on Decision-making of Supplier's R\&D Vertical Knowledge Spillover. Ind. Eng. Manag. 2008, 4, 29-31.

45. Dockner, E.; Jorgensen, S.; Van, L.; Sorger, G. Differential Games in Economics and Management Science; Cambridge University Press: Cambridge, UK, 2000; pp. 41-42.

46. Jeang, A.; Rahim, A. Lot size determination for finite horizon under the effect of productivety and quality learning process. Int. J. Syst. Sci. Oper. Logist. 2018, 1-44. [CrossRef]

(C) 2019 by the authors. Licensee MDPI, Basel, Switzerland. This article is an open access article distributed under the terms and conditions of the Creative Commons Attribution (CC BY) license (http://creativecommons.org/licenses/by/4.0/). 